\title{
Correspondence Analysis in Attitudinal Research: The Case of World Englishes and Teaching English as an International Language
}

\author{
P. J. Hassall
}

Zayed University, Dubai

\section{S. Ganesh}

Massey University, New Zealand

"The model must fit the data, not vice versa" - Jean-Paul Benzecri (1977)

\begin{abstract}
This paper provides a further investigation into the application of Correspondence Analysis (CA) as outlined by Greenacre (1984, 1993), which is one technique for "quantifying qualitative data" in research on learning and teaching. It also builds on the utilisation of CA in the development of the emerging discipline of English as an International Language provided by Hassall and Ganesh (1996, 1999). This is accomplished by considering its application to the analysis of attitudinal data that positions the developing pedagogy of Teaching English as an International Language (TEIL) (see Hassall, 1996a \& ff.) within the more established discipline of World Englishes (cf. Kachru, 1985, 1990). The multidimensional statistical technique Correspondence Analysis is used to provide an assessment of the interdependence of the rows and columns of a data matrix (primarily, a two-way contingency table). In this case, attitudinal data, produced at a number of international workshops which focused on the development of a justifiable pedagogy for Teaching English as an International Language (TEIL), are examined to provide a more complete picture of how these venues differed from each other with respect to the collective responses of the respondents. CA facilitates dimensionality reduction and provides graphical displays in low-dimensional spaces. In other words, it converts the rows and columns of a data matrix or contingency table into a series of points on a graph. The current study presents analyses of two different interpretations of this data.
\end{abstract}

\section{Introduction}

This paper discusses the use of a statistical technique (Correspondence Analysis) which can help researchers to identify relative tendencies in people's responses to a range of issues. A 
workshop was held at five international venues focussing on English Language Teaching and a presentation was made of the developing pedagogy of Teaching English as an International Language (Hassall, 1996a \& ff.). At these workshops, the participants were asked to provide autobiographical information related to World Englishes, and also to express their attitudes to tentative statements or "insights" concerning Teaching English as an International Language (TEIL) and to more well-known insights related to World Englishes (WE). This data was presented to the statistical instrument Correspondence Analysis (CA) in order to position TEIL within the more established WE paradigm. Correspondence Analysis was chosen for this task as the authors had previously used the approach in the analysis of linguistic data (Hassall, 1998a; Hassall \& Ganesh, 1996, 1999), and were interested in exploring the application of Correspondence Analysis to attitudinal data. There were two major reasons for undertaking the study:

a) to determine whether the five venues may be differentiated solely with reference to the relative strength of the responses to the various insights.

b) to determine whether the workshop responses showed new insights to TEIL \& WE to be more or less contentious, acceptable/unacceptable than more established insights to TEIL \& WE.

\section{The Study}

\section{Background to Attitudinal Research and Correspondence Analysis}

Researchers in the social sciences, as well as educators, are constantly faced with the need to "quantify qualitative data". For example, an instructor might wish to gauge students' response to certain concepts across more than one course; or a course coordinator in any subject might wish to quantify data resulting from student feedback, itemizing strength of students' response to different features which are shared by a number of courses of instruction. In market research an evaluation might be made of responses to an opinion poll or similar survey that considers strength of response to a number of features shared by different products.

In the present study, the collective responses of workshop participants to a number of insights related to the new pedagogy of TEIL were investigated with reference to the strength of the participants' reactions at different conference venues. Correspondence Analysis is an appropriate multivariate statistical technique for this kind of task, since it 
facilitates dimensionality reduction (bringing out overall patterns in people's responses), and provides relatively simple and intuitive graphical displays. The most basic form of CA employs a contingency table of just two categorical variables, and generates the 'correspondence' of categories of variables, which forms the basis for developing graphical displays. This enables us to compare the relationship between the two categorical variables - In this case, the particular insights and the workshop locations - with reference to the strength of the participants' responses. In the graphical display of CA that is produced, proximity of points indicates the level of association among row and/or column categories.

In statistical terms, CA provides a weighted Principal Component Analysis (PCA) of a contingency table, enabling a low dimensional configuration of the association between the rows and the columns. Once the contingency table is presented to CA, the procedure yields a conditional expectation for each row-column combination of categories. These values are normalized, and then a process defines the lower-dimensional solutions. The total inertia is decomposed to represent the new dimensions ready for the graphical display, and this total inertia is a measure of total variation of the elements in the table. The number of maximum (new) dimensions which is obtainable equals one less than the smallest number referring to either rows or columns (this is usually expressed as $\{\min ($ no. of rows, no. of columns) -1$\}$ ). The resulting 'low dimensionality lollows the rows and columns to be plotted simultaneously as points on a single chart. The axes of this low-dimensional configuration are called 'principal axes' and are arranged so that the first principal axis, conventionally lying horizontally, accounts for most of the inertia, the second vertical principal axis explains the second largest percentage of inertia and so on. It should be noted here that the plot should be thought of as two different overlaid plots, one for each categorical variable (ie. rows and columns representing insights and venues). Distances between category points within a variable (ie. distances between rows or between columns) have meaning, but distances between category points from different variables (ie. between a row representing an 'insight' and a column representing a venue) do not. It is important to note when considering the graphic displays, that the points that lie closer to the origin with respect to a principal axis contribute very little to the inertia explained by that axis. Thus, a principal axis can be 'characterised', even given a title, depending on which categories of rows and/or columns contribute the most to that particular axis.

\section{Venues for the workshops}

Five different venues were considered for the present study, and an identical attitudinal response task was given to each of the participants at all the venues. The aim was to 
contrast the five workshops with reference to their collective responses to insights relating to the developing pedagogy of Teaching of English as an International Language (TEIL) within the more established World Englishes paradigm. Because of the specialist nature of the venues, each group of 'experts' was composed of individuals who may be considered to have above average experience and skills in dealing with international English language education and cross-cultural contact. All the participants were either international students with first-hand experience of an international English education, or academics from a wide variety of global locations, involved in the discipline of World Englishes or expected to deal with international students who employ a wide variety of Englishes depending on their country of origin.

Participants at TEIL Workshops

IPC - International Pacific College, Palmerston North, New Zealand (Hassall, 1998b)

UIUC - University of Illinois at Urbana-Champaign, USA (Hassall, 1998c)

PSU - Portland State University, USA (Hassall and Brown, 1999)

TSU - Tsukuba Science City Convention Centre, Japan (Hassall, 1999a)

UWA - University of Western Australia, Perth, Australia (1999b)

\section{Sample Size}

9

8

10

11

The TEIL Workshops were all held between September 1998 and September 1999. Venues for these workshops included the International Pacific College Research Forum (September 1998), the 5th International Conference on World Englishes: World Englishes and African Identities, Urbana-Champaign, USA (IAWE5 - November 1998); the 6th International Conference on World Englishes: World Englishes and Asian Identities, Tsukuba, Japan (IAWE6 - July 1999); at the 24th Annual Congress of the Applied Linguistics Association of Australia, Perth, Australia (September 1999); and, with the kind assistance of Professor Kimberley Brown, as a supplement to the World Englishes course at Portland State University, USA (March 1999) Intuitively, all but the International Pacific College Research 
Forum included a high proportion of practitioners directly involved in the discipline of World Englishes [IPC academics were involved in a number of other specialized disciplines including International Environmental Studies, International Relations, International Business, Global Communications and Tourism, for further background information on IPC see Hassall (1996b, 2002)]; all respondents to the survey, except for those on the Portland State University World Englishes course, were academics (lecturers/assistant professors and above); the workshop held at IAWE5, Tsukuba, Japan involved the most homogeneous group both culturally and linguistically.

At all the venues, Phase One of the workshop was approached by means of an audio-visual presentation, consisting of overhead transparency slides, shown in bullet format, accompanied by a 'voice-over' audio-tape to ensure consistency of presentation. This provided an introduction to 'TEIL Practicum and World Englishes' (see eg. Hassall, P. J. and K. Brown, 1999). Following this phase, participants were invited to undertake tasks similar to those likely to arise on an 'explicit course of TEIL' (Hassall, 1996a, 1996b) by completing a set of worksheets. Each set of worksheets was coded with a confidential, personal identification number (PIN), which allowed the scripts to be tracked anonymously.

\section{The Instrument}

In his introduction to Correspondence Analysis, Greenacre (1993:161-170) itemizes studies involving ratings to describe strength of response. He discusses variations on the customary five-point Likert scale and introduces an example of investigation into reviewers' ratings of graphics textbooks, which refer to several criteria, with each rating scale being a 10-point scale with 1 indicating "very poor" and 10 "excellent". He also discusses the example of a survey which was conducted amongst females to establish their usage and perception of major retail clothing stores. In this survey each respondent was asked what importance she placed on a set of attributes relating to clothing stores. Their responses were rated on a seven-point scale of importance, where 1 indicated "extremely unimportant" and 7 "extremely important".

The present study involved data collection activities designed to ascertain participants' attitude to ideas about TEIL and World Englishes. One of the tasks involved participants recording their responses to three sets of six insights (listed in the Appendix to this paper). Two of the insight categories - Insights from TEIL Practicum (coded $p^{\star}$ ) and Insights from current research (coded $r^{*}$ ) - originated in the work of one of the current authors (Hassall, 1996c). The third category - Insights from contemporary World Englishes literature (coded 
we* ${ }^{*}$ was selected from writings authored by notable academics who had contributed to the seminal volume edited by Smith and Forman (1997). As shown below, the instrument that was used to collect attitudinal data was a graphical scale from strongly disagree (-) on the left, to strongly agree $(+)$ on the right, centered about zero. Considering both points and intermediary positions on this line allowed scores from minus seven, through zero to plus seven to be identified and aggregated for each of the insights under scrutiny.

Individual Response: Indicate your disagreement/agreement with the following statements by placing one cross $(\boldsymbol{X})$ on the scale.

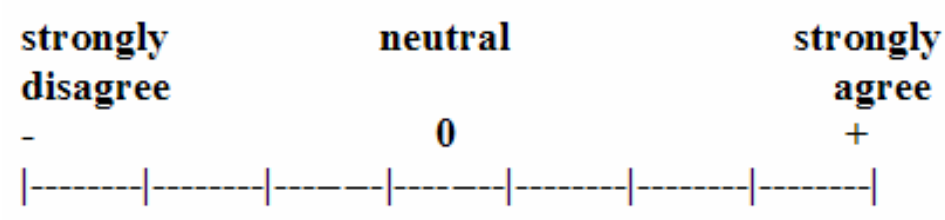

Insights from TEIL Practicum $\left(\mathbf{p}^{1}-\mathbf{p}^{6}\right)$

Insights from current research $\left(\mathbf{r}^{1}-\mathbf{r}^{6}\right)$

Insights from contemporary WE literature $\left(\mathbf{w e}^{1}-\mathbf{w e}^{6}\right)$

Initially, an aggregate score for each of the insights was assembled using all positive values to the right of the mid point to strongly agree $(+7)$ for each of the venues. All of the venues displayed positive values for each of the insights and this enabled a two-way contingency table to be assembled. In total there were 2816 positive values distributed over a total of 18 insights and five venues.

\section{Analysis and Interpretation of Results}

\section{Interpretation: Positive Responses}

A major aim of carrying out the correspondence analysis was to determine whether the five venues may be differentiated solely with reference to the relative strength of participants' responses to the various insights. The present study examines all eighteen of the insights relating to TEIL, divided into the three categories $p^{*}, r^{*}$ and $w e^{*}$, shown above. Each of these insights scored a positive response of between +5 and +62 in the aggregate result from each of the workshop venues. A contingency table showing relative strength of response to these insights against the five locations is shown in Table 1. 
Table 1. Contingency Table showing the 3 categories of insights distributed against location of workshops for positive $(+)$ responses

\begin{tabular}{|c|c|c|c|c|c|c|}
\hline & IPC & UIUC & PSU & TSU & UWA & Total \\
\hline p6 & 49 & 62 & 53 & 54 & 34 & 252 \\
\hline p1 & 18 & 54 & 49 & 59 & 49 & 229 \\
\hline p2 & 23 & 53 & 49 & 47 & 37 & 209 \\
\hline we3 & 34 & 52 & 33 & 42 & 39 & 200 \\
\hline p3 & 41 & 40 & 45 & 31 & 36 & 193 \\
\hline p5 & 30 & 30 & 38 & 45 & 27 & 170 \\
\hline we2 & 26 & 51 & 31 & 30 & 31 & 169 \\
\hline we5 & 29 & 39 & 28 & 39 & 25 & 160 \\
\hline p4 & 27 & 39 & 43 & 20 & 27 & 156 \\
\hline$r 1$ & 25 & 30 & 24 & 36 & 22 & 137 \\
\hline$r 2$ & 19 & 49 & 20 & 28 & 17 & 133 \\
\hline$r 5$ & 15 & 31 & 31 & 38 & 18 & 133 \\
\hline$r 3$ & 6 & 32 & 29 & 33 & 27 & 127 \\
\hline we1 & 5 & 39 & 20 & 44 & 18 & 126 \\
\hline$r 6$ & 10 & 29 & 34 & 38 & 11 & 122 \\
\hline we 6 & 23 & 34 & 26 & 13 & 20 & 116 \\
\hline$r 4$ & 22 & 25 & 13 & 30 & 10 & 100 \\
\hline we4 & 15 & 6 & 13 & 41 & 9 & 84 \\
\hline Total & 417 & 695 & 579 & 668 & 457 & 2816 \\
\hline
\end{tabular}


To facilitate interpretation, the data is submitted to Correspondence Analysis, which produces a two-dimensional graphic representation of the two data sets (rows and columns), overlaid upon each other. The procedure of Correspondence Analysis is readily available as part of a number of statistical packages including the SAS System (SAS System, 1999; see Hassall \& Ganesh, 1996, 1999). CA as appears in the present study was part of a Microsoft Excel 'add-in' named XLSTAT, authored by Thierry Fahmy in Paris. XLSTAT was very easy to access and use, since it is now available through the Internet (Fahmy, 1995; XLSTAT, 2000).

The decomposition of the total inertia showed that the first principal axis accounts for $45 \%$ of this total inertia, followed by a $30 \%$ explained by the second principal axis. In other words, $75 \%(=45 \%+30 \%)$ of the information can be accounted for by the first two principal axes, thus the association between the 18 insights considered and the five venues is mainly twodimensional. Noting that the maximum number of new dimensions in this study is 4 , i.e. $\min (18,5)-1$, completeness of description provided by the extra dimensions (accounting for $25 \%$ of the total inertia) would be at the expense of clarity and ease of reference. 
Figure 1. Graphical Representation of CA for Positive Responses

Row Profiles and Column Profiles on axes 1 and 2 (75\%)

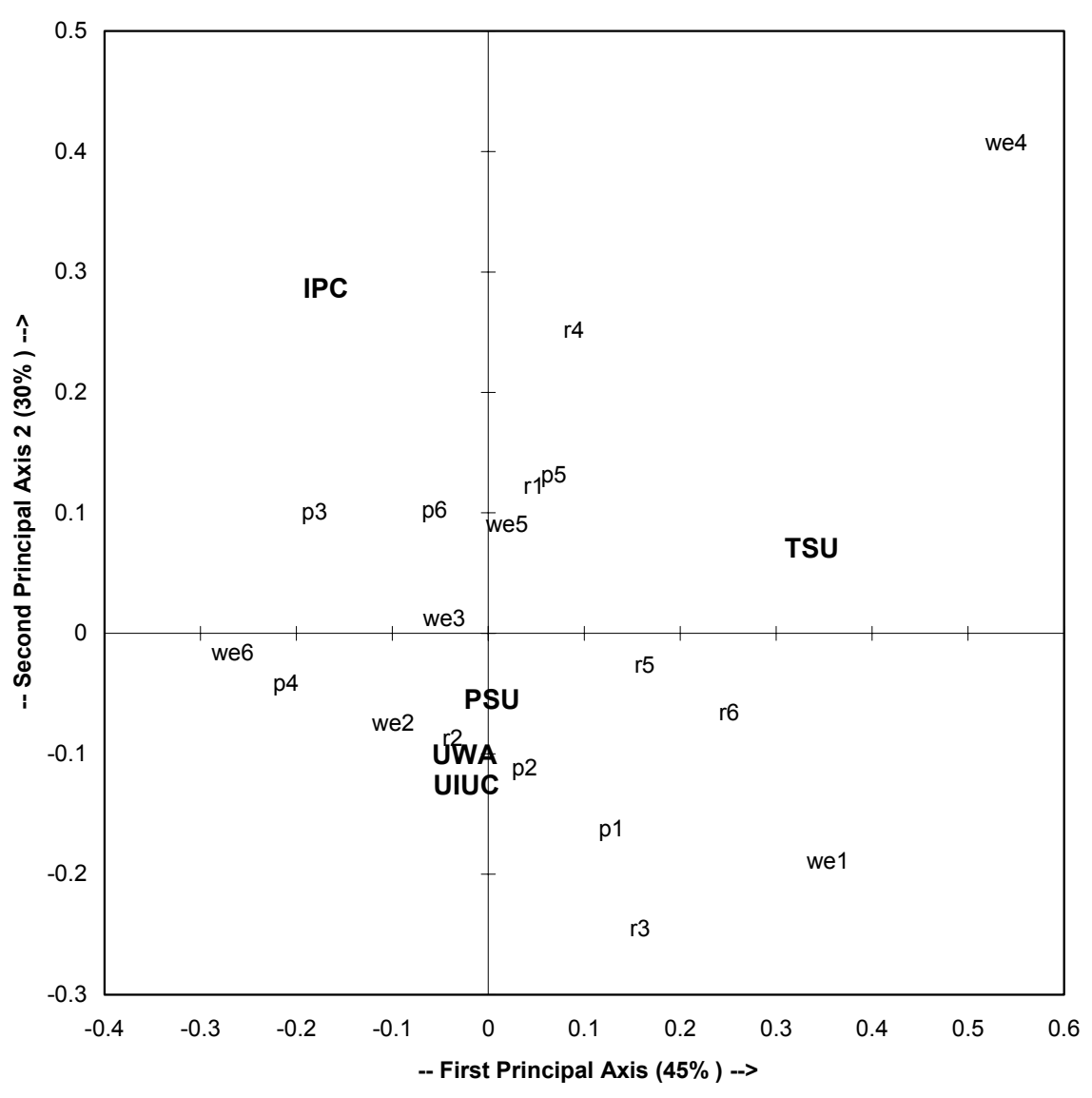

Figure 1 provides a two-dimensional summary of the association between venues and insights. This is similar to providing a representation of the spherical world onto a flat surface. In map-making, different projections maintain certain aspects of the data and can show accurate representation of direction, distance or area only at the expense of other features. In Figure 1, $75 \%$ of the information provided by the contingency table is represented along the first and second principal axes, and dimensions 3 and 4 are not being considered. The correspondence between the strength of agreement towards the 18 insights in 3 different categories and the 5 workshops is displayed on this graph, showing the order of magnitude between the venues and amongst the insights may be seen. Variation from left to right, along the first (horizontal) principal axis, opposes the IPC venue against the TSU venue, with contributions from PSU, UWA, UIUC being minimal; a further contrast from top to bottom along the second principal axis, on the other hand, opposes IPC against UIUC and UWA, with PSU and TSU making only a minor contribution to the variation since they are in 
close proximity to the origin. The behaviour of insights reveals a contrast between items such as we6, $p 4$ and $p 3$ against we4, we 1 and $r 6$ along the first principal axis, with items we2, $p 6$, and $r 3, r 5, p 1$ making a moderate contribution to this contrast. The second dimension accounts mainly for the differences between we 4 and $r 4$ against $r 3$, we 1 and $p 1$.

Correspondence between the aggregated responses to insights and the different workshops is not a straightforward matter since the graph is composed of two sets of points superimposed on each other. The general concept is that a particular workshop venue would tend to fall in a position which corresponds to insight items that are prominent for that particular workshop. Thus the TSU point lies furthest on the positive side of the first principal axis and any points referring to insights that lie on the positive side of the first axis, such as we4 and we1, may be regarded as 'influential' for that particular workshop.

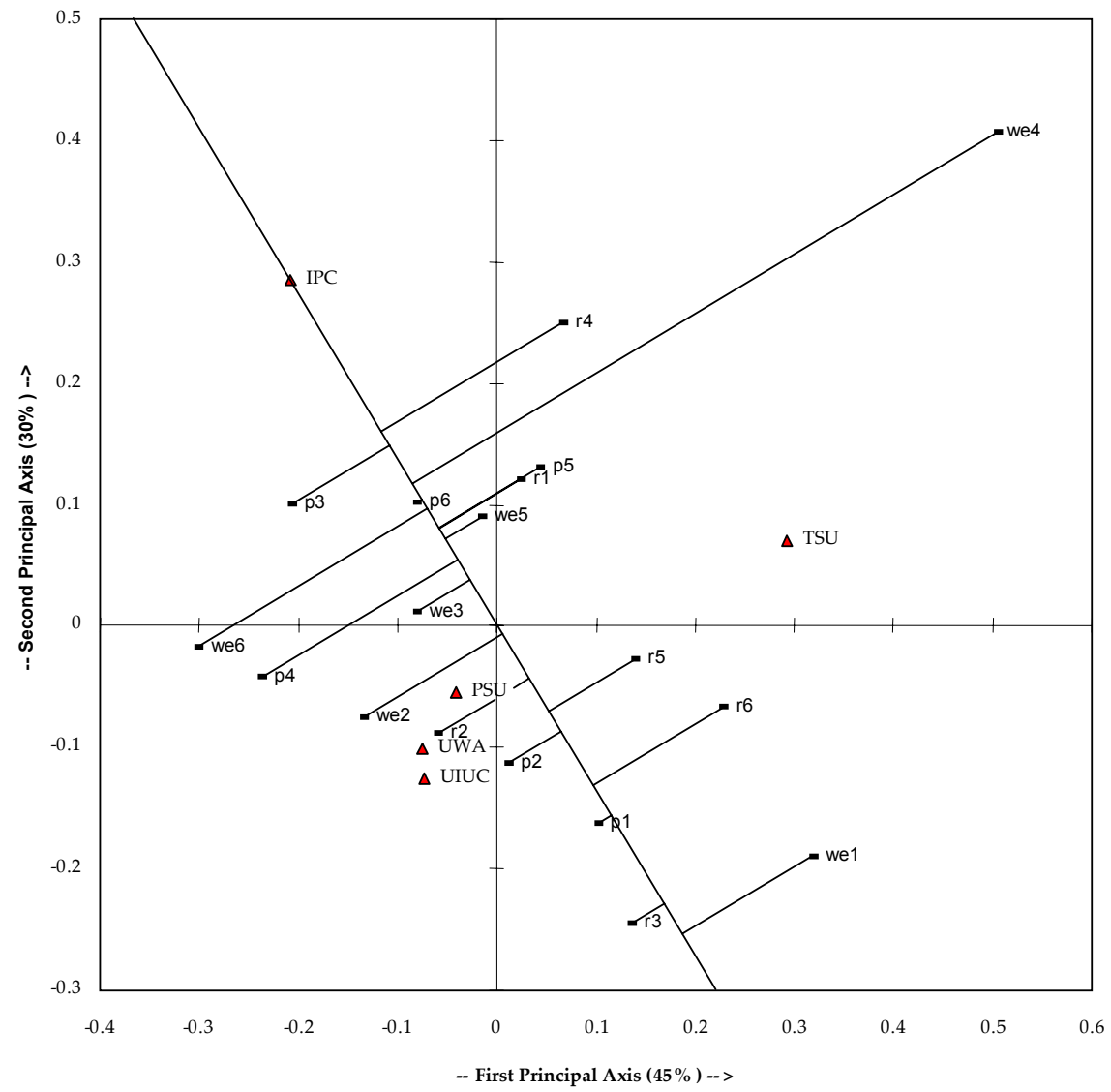

Figure 2. Projections of Insights onto the Secondary Axis through IPC

The relationship between the workshops and insights may be examined by considering, in turn, projections of the 'insight points' onto lines drawn through each of the 'workshop points' and the origin on the graph. This enables the relationship between, for example, the IPC 
workshop and the 18 different insights to be elucidated as shown in Figure 2. This reveals that for IPC, r4 exerts the greatest positive influence on the workshop, or in other words makes the greatest possible contribution to its behaviour compared to the other venues and insights, whilst we1 makes the greatest negative contribution to its behaviour. However, those items that lie near to the origin do not exert a significant contribution to the difference between the workshops. This procedure is repeated with each of the workshops in turn and the data compiled into a further table, Table 2, which follows.

Table 2. Insights most influencing TEIL workshops

\begin{tabular}{|c|c|c|c|c|}
\hline $\begin{array}{l}\text { IPC } \\
\text { (NZ) }\end{array}$ & $\begin{array}{l}\text { UIUC } \\
\text { (US) }\end{array}$ & $\begin{array}{l}\text { PSU } \\
\text { (US) }\end{array}$ & $\begin{array}{l}\text { TSU } \\
\text { (JPN) }\end{array}$ & $\begin{array}{l}\text { UWA } \\
\text { (AUS) }\end{array}$ \\
\hline$r 4$ & $r 3$ & $r 3$ & we4 & $r 3$ \\
\hline p3 & we6 $=$ & we 6 & we1 & we 6 \\
\hline we 4 & $p 4=$ & $p 4$ & $r 6$ & $p 4$ \\
\hline$p 6$ & $p 1$ & we2 & $r 4$ & we2 \\
\hline we 6 & we2 & $r 2=$ & $r 5$ & $r 2=$ \\
\hline p5 & $r 2$ & $p 1=$ & p5 & $p 1=$ \\
\hline$r 1$ & p2 & p2 & $r 1$ & p2 \\
\hline we5 & we1 & we1 & $r 3$ & we1 \\
\hline$p 4$ & we3 & we3 & $p 1$ & we3 \\
\hline we3 & $r 6$ & p3 & we5 & p3 \\
\hline we2 & $r 5=$ & $r 6=$ & p2 & $r 6=$ \\
\hline$r 2$ & $p 3=$ & $r 5=$ & $p 6$ & $r 5=$ \\
\hline$r 5$ & $p 6$ & $p 6$ & we3 & $p 6$ \\
\hline p2 & we 5 & we 5 & $r 2$ & we 5 \\
\hline
\end{tabular}




\begin{tabular}{|c|c|c|c|c|}
\hline$r 6$ & $r 1$ & $r 1$ & we2 & $r 1$ \\
\hline$p 1$ & $p 5$ & $p 5$ & $p 3$ & $P 5$ \\
\hline r3 & $r 4$ & $r 4$ & $p 4$ & $r 4$ \\
\hline we1 & we4 & we 4 & we6 & we4 \\
\hline
\end{tabular}

In Table 2, the clear cells refer to the insights from the literature relating to the more established discipline of World Englishes (Smith \& Forman, eds. 1997) whilst the light and dark cells refer to insights from TEIL Practicum $\left(p^{*}\right)$ and current research $\left(r^{*}\right)$ respectively (Hassall, 1996c). The cells towards the top of the table show insights that exert the most positive influence or attraction on a particular workshop venue and those towards the bottom of the table show those insights that exert the most negative influence or repulsion on a particular workshop when compared to the other workshops in the group. Equals signs on two consecutive cells indicate that no difference may be discerned between the weight of two successive items. Significant similarity may be seen between the positive influence of the insights $r 3$, we6, $p 4$, we2, $r 2, p 1, p 2$ and we1 for the workshop venues UIUC, PSU, UWA. Reference to Figure 1. shows that although the insight item $r 3$ exerts the strongest positive influence, the influence of the other insights does not decrease substantially, explaining that this mixed group of eight insights exerts a consistently powerful positive influence on the three workshop venues. However, IPC and TSU demonstrate very different behaviours. Of the aforementioned eight insights, the item we1 exerts a strong positive influence on TSU, whereas IPC is attracted more by we6. These items we1 and we6 help to account for the contrasting behaviour of these two workshop venues, with we1 repelling IPC and TSU being negatively influenced by we6. This is reinforced by $r 6$ and $p 3$, which exert a positive influence on TSU and IPC respectively, yet similarly apply a complementary negative influence on the opposite venue. Jointly, IPC and TSU may be characterised by the positive behaviour of the insight items we4, $r 4$ and to a lesser extent $p 5, r 1$. The strong positive influence of these four insights on IPC and TSU is counterbalanced by their strong negative influence on the contrasting group of workshop venues, UIUC, PSU and UWA.

In summary, UIUC PSU and UWA may be characterised by the positive influence of varied insights $(r 3$, we $6, p 4$, we2, $r 2, p 1, p 2 \&$ we1), and these venues contrast with the behaviour of IPC and TSU, which are positively influenced by a different group of insights (we4, r4, p5 \& r1). IPC and TSU, however, are clearly distinguished from each other, for example by the 
contrasting behaviour of we 1 and $r 6$ (which attract TSU and repel IPC) and we 6 and $p 3$ (which attract IPC and repel TSU). It is significant that in no case is a particular group of insights preferred or repulsed by any of the venues.

\section{Interpretation: Emotive Responses}

The discussion above focuses on the positive responses; a further interpretation of the data was undertaken by adding in the negative responses, thus considering strength of response, both positive and negative, at each of the venues towards each of the insights. Such responses may be termed emotive responses, since they represent the total strength of feeling towards each of the insights.

Table 3 shows the additional negative responses required to be added in to produce a new contingency table representing emotive responses. Thus, high scores will provide some indication of likely controversy - showing strength of feeling towards particular insights. A parallel methodology was used to generate CA and its graphical representation for emotive responses.

Figure 4 provides a two dimensional representation of CA for emotive responses showing the first two principal axes, which account for $78 \%$ of the information. Variation from left to right (along the first principal axis) opposes the UWA venue against IPC, with a further contrast from top to bottom (along the second principal axis), which opposes TSU against UIUC with PSU making little contribution to the variation.

The behaviour of insights reveals a contrast between items such as we $4 p 3$ and $p 5$ against we1 and $r 3$ along the first principal axis. The second dimension accounts mainly for the contrast between we 4 and $r 6$ against we 6 and $p 4$. When compared to Figure 1 , it may be appreciated that the IPC and TSU venues have repositioned appreciably in relation to the other workshop venues. However, the influence of particular insights relating to IPC has not changed so significantly. 
Table 3. Contingency table showing the TEIL insights distributed against location showing change from positive $(+)$ to emotive $(+\&-)$ responses

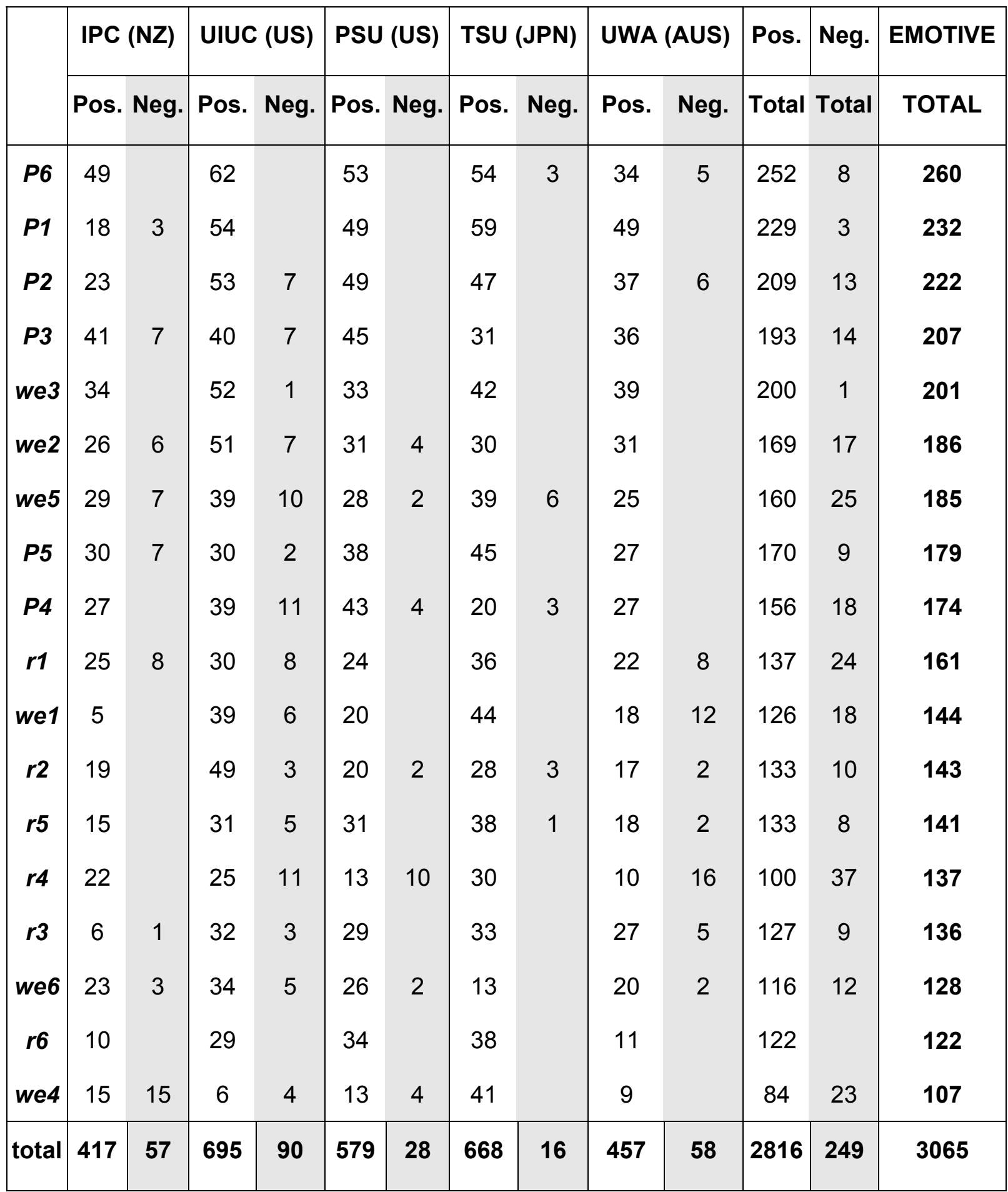


Figure 4. Graphical representation of CA for Emotive Responses

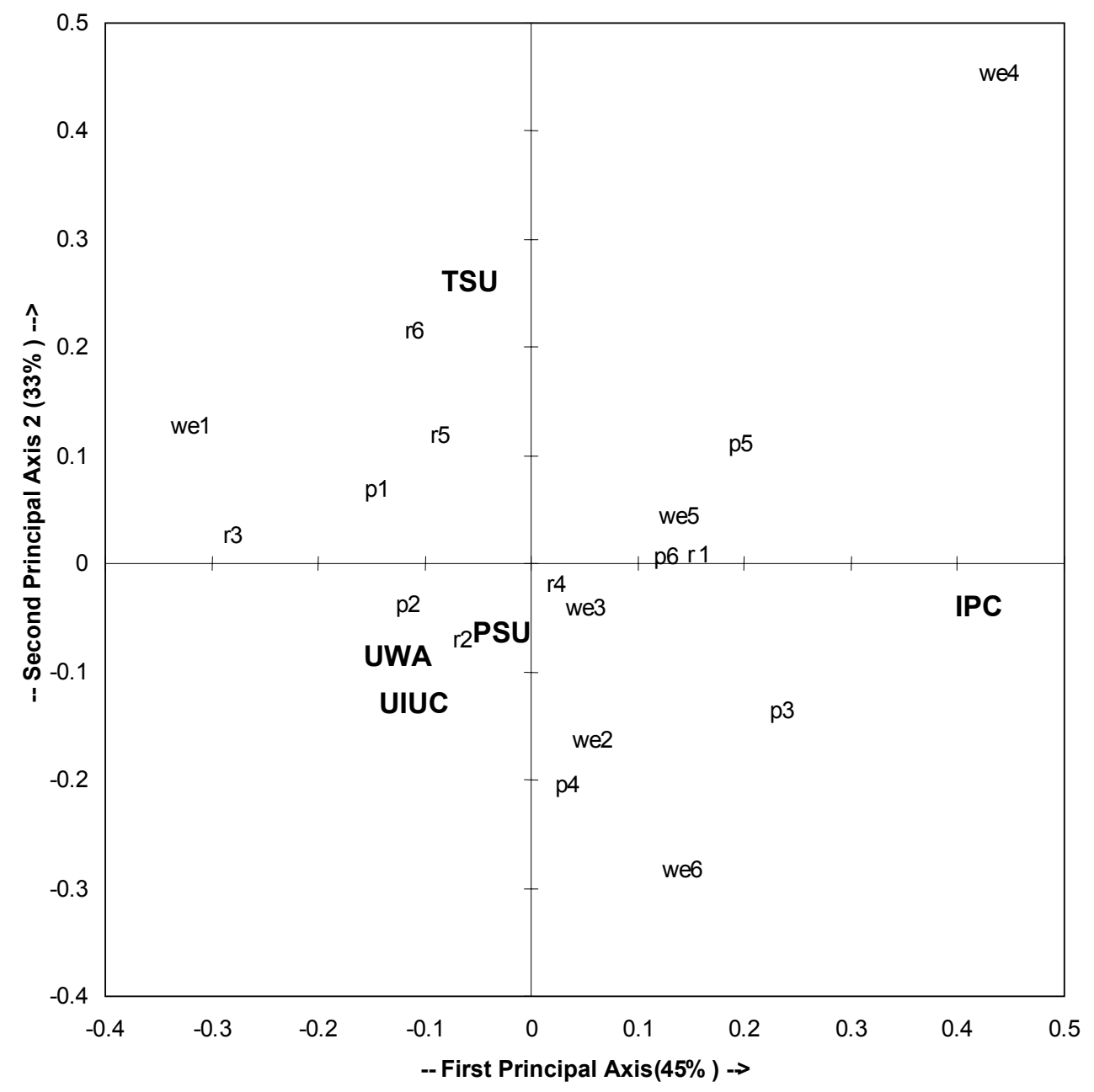

Figure 4 reveals that we $4, p 3$ and $p 5$ exert the greatest positive influence on IPC when considering emotive responses, compared to $r 4, p 3$ and we4 (as appears in Figure 2, which represents the participants' positive reactions). Scrutiny of figure 4 shows that emotive responses exerting the greatest negative influence on IPC are we1, $r 3$ and $p 1$. These are the same as when considering positive responses only. Table 4 facilitates interpretation of information relating to emotive responses that influence respective venues showing those insights that attract particular workshops towards the top of the table and those that repel towards the bottom of the table.

In Table 4 the most controversial insights, which attract the greatest attention, appear to be we4 and $r 3$. The venues IPC and TSU are strongly attracted by we4. In contrast UIUC and UWA are clearly attracted by $r 3$. The emotive insight we1 exerts positive attraction for all but IPC, which is more strongly influenced by $p 3$ and $p 5$ when compared to the other venues. The insight $p 4$ clearly attracts both UIUC and PSU, whereas $r 6$ helps characterize the 
behaviour of the venue TSU. The location PSU, which contributes least to the variation, is most attracted by the emotive insight we6, which to a lesser extent also attracts UIUC and IPC.

Table 4. Emotive insights most influencing workshop venues

\begin{tabular}{|c|c|c|c|c|}
\hline $\begin{array}{l}\text { IPC } \\
\text { (NZ) }\end{array}$ & $\begin{array}{l}\text { UIUC } \\
\text { (US) }\end{array}$ & $\begin{array}{l}\text { PSU } \\
\text { (US) }\end{array}$ & $\begin{array}{c}\text { TSU } \\
\text { (JPN) }\end{array}$ & $\begin{array}{l}\text { UWA } \\
\text { (AUS) }\end{array}$ \\
\hline we 4 & $r 3$ & we6 & we4 & $r 3$ \\
\hline p3 & p4 & $p 4$ & $r 6$ & we1 \\
\hline p5 & we 6 & we2 & we1 & p2 \\
\hline we6 & $p 2$ & $r 2$ & $r 5$ & $r 2$ \\
\hline$r 1$ & we1= & p2 & $p 1$ & $p 1$ \\
\hline p6 & we2= & r3 & p5 & p4 \\
\hline we 5 & $r 2$ & p3 & $r 3$ & we2 \\
\hline we2 & $p 1$ & we3 & we5 & we6 \\
\hline$p 4$ & we3 & $r 4$ & $p 6$ & $r 5$ \\
\hline we3 & $r 4$ & we1 & $r 1=$ & $r 4$ \\
\hline$r 4$ & $r 5$ & $p 1$ & $p 2=$ & we3 \\
\hline$r 2$ & p3 & p6 & $r 4$ & $r 6$ \\
\hline r5 & p6 & $r 1$ & we3 & p6 \\
\hline$p 2$ & $r 1$ & $r 5$ & $r 2$ & p3 \\
\hline$r 6$ & $r 6$ & we5 & we2 & $r 1$ \\
\hline$p 1$ & we 5 & $r 6$ & p3 & we5 \\
\hline
\end{tabular}




\begin{tabular}{|c|c|c|c|c|}
\hline$r 3$ & $p 5$ & $p 5$ & $p 4$ & $p 5$ \\
\hline we1 & we4 & we4 & we6 & we4 \\
\hline
\end{tabular}

Table 4 explains that for all the venues, the TEIL Practicum and research insights originating in Hassall (1996c) are not considered more controversial than those from contemporary World Englishes literature (clear cells), which are distributed evenly over the table. Contiguous shaded cells, relating to the practicum and research, are evident towards the bottom of the table for IPC and UIUC. This might indicate familiarity or openness to new ideas.

\section{Implications and Conclusions}

A major motivation for undertaking this study was to consider responses to the twelve insights focusing on the Teaching of English as an International Language (TEIL) originated by one of the authors (Hassall, 1996c) and to compare the behavior of these insights ( $p^{*}$ and $\left.r^{*}\right)$ to those of six other insights originated by notable academics in the more established discipline of World Englishes $\left(w e^{*}\right)$. In the present study, the correspondence analysis of positive responses in Table 2 showed no particular preferences in favor of the insights originating in the World Englishes literature, with clear cells being distributed evenly throughout the table. This was gratifying because it demonstrates that the insights originating in Hassall (1996c) were given as much attention and positive acknowledgement by the respondents in this survey as the other insights originating in Smith and Forman (eds., 1997). When considering positive responses, a contrast was evident between the Japanese TSU venue which favored the research insights $\left(r^{\star}\right)$ and the New Zealand IPC venue which displayed complementary behaviour. Two possible explanations for this may be suggested. First, the choices made at TSU in Japan may be linked to the high proportion of first-language users of Japanese, having a certain predilection for these insights. Conversely the IPC venue, comprising the most disparate group of academics most likely involved in subjects other than World Englishes, the subject of the workshops, came from New Zealand and generally exhibited contrasting behaviour. There was more consistency of opinion when considering the workshops held in the United States and Australia with participants who were informed academics or students of World Englishes, who favoured a more balanced set of choices. 
Table 4, CA of emotive responses, shows that none of the groups appeared to find the insights authored in Hassall (1996c) more controversial than those originating in the World Englishes literature (Smith \& Forman eds., 1997). Participants at the IPC venue, which had been the workplace of the originator of the $p^{*}$ and $r^{*}$ insights for a number of years and was the venue that comprised the academics with least knowledge of the discipline of World Englishes, displayed almost the converse reaction emotively and found the $p^{*}$ and $r^{*}$ insights less contentious. This would suggest that when considering a new paradigm such as an English as an International Language grounded in World Englishes, the concept of familiarity is significant. This conclusion corroborates the findings of Brown and Peterson (1997) who, when investigating the implementation of the (then) new perspective of World Englishes, found it takes a minimum of 30 hours exposure prior to workshop participants becoming familiar with and adept at handling new concepts.

It is hoped that the present study may help revitalize the study of World Englishes and help provide a direction for a TEIL pedagogy that is consistent with the objectives of the International Association of World Englishes (IAWE). According to its web-site, IAWE, "Aims to establish international links among those who are involved with any aspect of World Englishes in research and/or teaching. The association focuses on global issues relating to three major aspects of World Englishes: language, literature and pedagogy." $<$ http://www.iaweworks.org/>.

\section{Reflection/Discussion Questions}

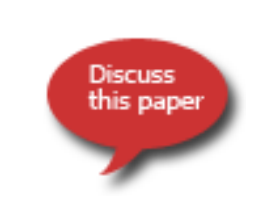

1. Does your teaching or other work in education involve any collection of data relating to attitudes? How could you gather and analyze useful data, e.g. from students?

2. Are there questions of attitude that relate to the development of your academic discipline? How could you gather data on these?

3. Are localized and global perspectives important to the development of your academic discipline in the same way that World Englishes and Teaching English as an International Language are likely to be influential to the teaching of English worldwide?

\section{About the Authors}

Peter Hassall of the English Language Center, Zayed University, Dubai, has three times received awards from the English Speaking Union English (ESU) presented at Buckingham Palace by HRH the Duke of Edinburgh, President of the ESU. His research interests include the development of ELT, English as an International Language and World Englishes. 
Siva Ganesh is Senior Lecturer in Statistics and Data Mining at the Institute of Information Sciences \& Technology, Massey University, Palmerston North, New Zealand. He obtained his MSc (Biometry) and PhD from University of Reading, UK. His research interests include dimensionality reduction in multivariate data, statistical computing and data mining.

\section{References}

Benzecri, J. P. (1977). Statistical analysis as a tool to make patterns emerge from data. In Methodologies of Pattern Recognition (Watanabe, S, ed.), pp 35-74. New York: Academic Press.

Brown, K. \& J. Peterson (1997). Exploring conceptual frameworks: framing a World Englishes paradigm. In Smith, L. E. \& Michael L. Forman (eds.) World Englishes 2000. Literary Studies East and West 14. Honolulu: : College of Languages, Linguistics and Literature University of Hawai'i and the East-West Center.

Fahmy, T. (1995). XLSTAT. <http://www.xIstat.com>.

Greenacre, M J (1984). Theory and Applications of Correspondence Analysis. London: Academic Press.

Greenacre, M. J. (1993). Correspondence Analysis in Practice. London: Academic Press.

Hassall, P. J. (1996a). TEIL: a methodology. Abu Dhabi: The HCT Journal, 1(2), 13-22.

Hassall, P. J. (1996b). Implementing EIL: the Medium Really is the Message. New Zealand Studies in Applied Linguistics, 2, 57-77 (ERIC Document Reproduction Service No. ED 413 734).

Hassall, P. J. (1996c). Towards the Analysis of Deviance in English as an International Language. Unpublished Manuscript.

Hassall, P. J. (1998a). Unity in Diversity: towards an integrated paradigm of English as an International Language and World Englishes including MAVEN. The major varieties of English. Papers from MAVEN 97. Edited by Hans Lindquist, Staffan Klintborg, Magnus Levin and Maria Estling, 291-301. Växjö: Acta Wexionensia.

Hassall, P. J. (1998b). TEIL Practicum and World Englishes: a Workshop. International Pacific College Research Forum, September, 1998, New Zealand: International Pacific College. 
Hassall, P. J. (1998c). TEIL Practicum and World Englishes: a Dialogue. Workshop presented at the 5th International Conference on World Englishes: World Englishes and African Identities, November 1998, USA: Urbana-Champaign.

Hassall, P. J. (1999a). Workshop: TEIL Practicum insights for World Englishes. Presented at the 6th International Conference on World Englishes: World Englishes and Asian Identities, July 1999, Japan: Tsukuba.

Hassall, P. J. (1999b). Workshop - TEIL Practicum and World Englishes: Issues for ELT. 24th Annual Congress Applied Linguistics Association of Australia, September 1999. Perth: University of Western Australia.

Hassall, P. J. (2002). TEIL: English as an International Language and the needs of Pacific Rim Countries. Asian Englishes, 4(2) 72-101.

Hassall, P. J. \& K. Brown (1999). Workshop: TEIL Practicum insights for World Englishes.(audio-tape \& worksheets) as part of a World Englishes course offered through the department of Applied Linguistics, Portland State University, Spring Term 1999.

Hassall, P. J. \& S. Ganesh (1996). Correspondence Analysis of English as an International Language. The New Zealand Statistician, 31(1), 24-33.

Hassall, P. J. \& S. Ganesh (1999). Correspondence analysis of international relative deviance. The on-line conference "Language typology", Web Journal of Formal, Computational \& Cognitive Linguistics, May, 1999. Kazan University: Russian Association of Artificial Intelligence (FCCL). pp. 1-22. <http://fccl.ksu.ru/fcclroot.htm>

Kachru, B. B. (1985). Standards, codification and sociolinguistic realism: the English language in the outer circle. In Quirk, R. and H. G. Widdowson (Eds.) (1985) English in the world: teaching and learning the language and literatures, Cambridge: Cambridge University Press, 11-30.

Kachru, B. B. (1990). The Alchemy of English, University of Illinois: Illini Books.

Kachru, Braj B. 1997. World Englishes 2000: resources for research and teaching. In Larry E. Smith and Michael L. Forman (eds.), World Englishes 2000. Vol. 14. University of Hawaii: Literary Studies East and West. 
Smith, L. E. \& M. L. Forman, (Eds.) (1997) World Englishes 2000. Literary Studies East and West 14.Honolulu: College of Languages, Linguistics and Literature University of Hawai'i and the East-West Center.

SAS System (1999) Version 8.2 Edition, SAS Institute Inc. Cary, NC.

XLSTAT (2000) Version 4.4 Edition, AddinSoft SARL Co. <http://www.xlstat.com>

\title{
APPENDIX - WORKSHOP: TEIL Practicum insights for World Englishes.
}

\author{
PHASE THREE: Worksheet - Attitude towards TEIL and WE \\ For the purposes of this study a single word has been italicised
}

to provide a gloss for the whole citation

Insights from TEIL Practicum ( $\left.p^{*}\right)$ [Extracts from Peter J. Hassall, 1996c]

p1 The teaching of English should support and encourage communication between and across the three circles of English.

p2 To enhance international communication, study of Outer and Expanding World Englishes is equally as important as study of regional varieties of Inner Circle WEs.

p3 Negotiation of new meanings in cross-cultural communication is equally important as strict adherence to conventional forms and meanings.

p4 For the learner, Inner Circle World Englishes may appear as inconsistent as Outer and Expanding Circle World Englishes.

p5 A great deal of successful 'innovation' results from interaction between different World Englishes.

p6 Investigation into the diversity of World Englishes may be considered relevant for the construction of a general 'language awareness'. 
Insights from contemporary WE literature $\left(w^{*}{ }^{*}\right)$

[Extracts are from Smith, Larry E. and Michael L. Foreman eds. (1997) World Englishes 2000. Literary Studies East and West 14. University of Hawai'i and the East-West Center]

we1 EIL signals an international English in terms of acceptance, proficiency, functions, norms and creativity (Kachru, B.B., 1997:215).

we2 The 'colonization of the mind' should be criticized for legitimating the uncritical belief in the use and the superior status of English, or American or British varieties of English over other languages and other varieties (Tsuda, 1997:26).

we3 What is required is an English which can express the cultural identity of its users while retaining the practical social advantage of a language which is comprehensible nationally and internationally (Wright, 1996:154 cited in de Kadt, 1997:162).

we4 The world-wide strategies of indirection - linguistic, rhetorical, poetic, psychological - create a richness that to world majority students makes the spare, relentless logic of the western tradition seem meagre in comparison (Fox ,1994:21 cited in Kachru, Y., 1997: 64).

we5 The debate has to shift from a possibility of Good or Proper English as defined by Standard British or Standard American, to the question of what Englishes with all their diversity we want to celebrate (Pakir, 1997:180).

we6 One of the most challenging research areas which has mushroomed in the past one or two years is how to cope with variety of English used over the Internet by millions of young students (Tanake, S. personal communication cited in Alatis \& Straehle, 1997:3).

Insights from current research $\left(r^{*}\right.$.) [Extracts from Peter J. Hassall, 1996c]

$r 1$ For international purposes, an individual's capacity to converse across a number of WEs is more important than competence in any particular WE.

r2 Study of 'etic' features (as in phon'etics'), as well as 'emic' features (as in phon'emics'), is useful in distinguishing between disparate WEs.

r3 Research into the differences between disparate WEs could be undertaken by giving an identical task to different groups of WE users and comparing the language produced by each of the groups. 
r4 The notion of 'deviance' which is used to refer to degrees of creativity as well as error would be suitable for distinguishing between WEs.

r5 The teaching of English to language learners of all abilities and capacities provides the best context for increasing awareness of WEs and making them more widely available.

r6 Teaching of World Englishes (TWE) which teaches about 'retrospective' (backward-looking) patterning, may be complemented by TEIL* which explores 'prospective' (forward-looking) patterning. Note: ${ }^{*}(T E I L=$ a new perspective on Teaching English as an International Language).

\section{Notes}

${ }^{1}$ For further elucidation of the concept of low dimensionality see Greenacre $(1984,1993)$

${ }^{2}$ Citations for each of these workshops appear in the References 